\title{
QUALIDADE DA ÁGUA DESTINADA AO CONSUMO HUMANO EM IGUATAMA, MG, BRASIL
}

Luanna Marins Vieira Campos ${ }^{1}$, Michael Silveira Thebaldi ${ }^{2}$, Yasmin Fernandes Silva $^{3}$, Mariana Luíza da Silva ${ }^{1}$, Virgílio Henrique Barros Nogueira ${ }^{4}$

${ }^{1}$ Bacharela em Engenharia Civil pelo Centro Universitário de Formiga (UNIFOR $M G)$, Formiga - MG, Brasil.

${ }^{2}$ Professor Doutor do Departamento de Recursos Hídricos e Saneamento da Universidade Federal de Lavras (UFLA), Lavras - MG, Brasil. E-mail: michael.thebaldi@ufla.br

${ }^{3}$ Engenheira Ambiental e Sanitarista, mestranda em Recursos Hídricos em Sistemas

Agrícolas da Universidade Federal de Lavras (UFLA), Lavras - MG, Brasil

${ }^{4}$ Engenheiro Agrícola, mestrando em Recursos Hídricos em Sistemas Agrícolas da Universidade Federal de Lavras (UFLA), Lavras - MG, Brasil

Recebido em: 06/04/2019 - Aprovado em: 10/06/2019 - Publicado em: 30/06/2019 DOI: 10.18677/EnciBio_2019A187

\begin{abstract}
O abastecimento público de água é uma das principais preocupações da população e do Estado, sendo necessário então grandes investimentos em infraestrutura, devendo esta ser bem elaborada, com a presença dos mais diversos equipamentos e materiais, para se realizar a captação, tratamento e distribuição de água para a população, com qualidade e quantidade ideal. $\mathrm{O}$ objetivo foi determinar a qualidade da distribuição pública de água no município de Iguatama, MG, Brasil, proveniente de poços subterrâneos na rede de distribuição. Foram coletadas amostras de água em três reservatórios e duas torneiras residenciais, de janeiro a julho de 2017. Entre as análises físico-químicas, determinou-se o cloro residual livre, cor aparente, $\mathrm{pH}$ e turbidez, enquanto para as microbiológicas, o número de total Coliformes, Escherichia coli e bactérias heterotróficas. A classificação da potabilidade da água baseou-se nos parâmetros de qualidade impostos pela Portaria 2910/2011 do Ministério da Saúde. Em todas as avaliações realizadas o cloro residual livre manteve-se entre 0,2 mg/l e 1,2 mg/l, enquanto que em todas as análises foi registrado ausência de coliformes totais, Escherichia coli e bactérias heterotróficas. A partir da interpretação dos resultados obtidos, pôde-se concluir que qualidade da água amostrada estava de acordo ao preconizado pela legislação.
\end{abstract}

RESUMO

PALAVRAS-CHAVE: poços subterrâneos; rede de abastecimento de água; saneamento básico.

\section{QUALITY OF WATER INTENDED FOR HUMAN CONSUMPTION IN IGUATAMA, MG, BRAZIL}

\begin{abstract}
The public water supply is one of the main concerns of the population and of the State, requiring large investments in infrastructure, which must be well elaborated with the presence of the most diverse equipment and materials, for the catchment,
\end{abstract}


treatment and distribution of water for the population, with ideal quality and quantity. Thus, the paper aims to determine the quality of the public water distribution in the city of Iguatama, MG, Brazil, explored from underground wells. Water samples were collected in three reservoirs and two residential taps, from January to July 2017. Among the physicochemical analyzes, free residual chlorine, apparent color, $\mathrm{pH}$ and turbidity were determined, while for microbiological parameters, the total number of Coliforms, Escherichia coli and heterotrophic bacteria. The classification of water potability was based on the quality parameters imposed by Resolution number $2910 / 2011$ of the Ministry of Health. All evaluations of free residual chlorine remained between $0.2 \mathrm{~m} / \mathrm{l}$ and $1.2 \mathrm{mg} / \mathrm{l}$, whereas in all analyzes there were no total coliforms, Escherichia coli and heterotrophic bacteria. From the understanding of the results obtained, could be concluded that the quality of the water sampled was as required by legislation.

KEYWORDS: basic sanitation; underground wells; water supply network.

\section{INTRODUÇÃO}

Nos países emergentes, devido as baixas condições de saneamento, as doenças diarréicas de veiculação hídrica, como, febre tifóide, cólera, salmonelose, shigelose e gastroenterites, poliomielite, hepatite $A$, verminoses, amebíase e giardíase, são tomadas como causa de vários surtos epidêmicos e pelo aumento da taxas de mortalidade infantil, sendo as mesmas ligadas ao consumo de água (GOMES et al., 2016).

O saneamento ambiental, responsável por englobar o esgotamento sanitário, limpeza e drenagem urbana, controle de vetores de importância sanitária, tem como essencial o abastecimento de água. No Brasil, segundo o Datasus, as doenças relacionadas a deficiências no saneamento ambiental causaram cercaa de 3,4 milhões de internações no país, no período de 1995 a 1999. Sendo que segundo esses mesmos dados os serviços de saneamento ambiental poderiam ter evitado $80 \%$ dos casos de febre tifóide e paratifóide, $60 \%$ a $70 \%$ dos casos de tracoma e esquistossomose e de $40 \%$ a $50 \%$ das doenças diarréicas e outras parasitoses (CAMARGO-CRUZ, 2017).

De acordo com FUNASA (2015), o conceito de Sistema de Abastecimento de Água implica no conjunto de obras, instalações e serviços, destinados a fornecer água a uma comunidade, em quantidade e qualidade compatíveis com as necessidades da população, para fins de consumo doméstico, serviços públicos, consumo industrial e outros usos.

Os mananciais podem ser de águas superficiais ou subterrâneas. As águas superficiais são captadas em rios, lagos e reservatórios artificiais. Já as águas subterrâneas são provenientes de fontes como: poços, de galerias de infiltração e de bacias de captação ou de acumulação (VILLAR, 2016).

Segundo Libânio (2010), no Brasil, somente em 1977 com o surgimento da Portaria 56 foi estabelecido o primeiro padrão de potabilidade definindo os limites máximos para as diversas características físicas, químicas e biológicas específicas às águas de consumo humano. Posteriormente, o Ministério da Saúde publicou, em janeiro de 1990, a portaria 36, aumentando o número de parâmetros e tornando alguns limites mais restritivos. Anos depois, com implementação efetivada em janeiro de 2003, foi publicada a Portaria 1469. Em março de 2004, ela foi revogada, passando a vigorar a Portaria 518 mantendo-se inalterados o número e os valores máximos permissíveis de cada parâmetro. Além do padrão de potabilidade, a 
Portaria 518 estabeleceu os procedimentos e responsabilidades relativos ao controle e vigilância da qualidade da água.

Hoje, a portaria que rege os princípios de qualidade das águas de abastecimento no Brasil é a 2.914, criada em 12 de dezembro de 2011. Segundo RIBEIRO (2012), esta última versão da Portaria é resultado de um amplo processo de discussão para revisão da Portaria no 518/2004 do Ministério da Saúde, realizado no período de 2009 a 2011, sob a coordenação do Departamento de Vigilância em Saúde Ambiental e Saúde do Trabalhador da Secretaria de Vigilância em Saúde do Ministério da Saúde.

A maior parte da reserva de água doce em nosso planeta não é encontrada em forma potável. As águas subterrâneas, em sua grande parte advindas de poços, por não estarem expostas aos diversos agentes poluentes, no geral são menos contaminadas por fatores biológicos e químicos do que as águas superficiais. (BORGES et al., 2014). Porém, a diversificada utilização das águas subterrâneas é crescente e, com isso, aumenta a importância da qualidade dessas águas. Ademais, fatores como os esgotos domésticos e industriais e fertilizantes utilizados na agricultura, podem comprometer a qualidade dessas águas, tornando-as impróprias para consumo humano (ARAÚJO et al., 2018)

Portanto, para que a água subterrânea seja considerada potável, é necessária a realização de análises microbiológicas e físico-químicas, a fim de verificar se ela está dentro dos padrões de potabilidade para consumo humano estabelecidos nas normas vigentes no País (XAVIER et al., 2017).

Desta maneira, este trabalho teve como objetivo determinar a qualidade da água de distribuição pública no município de Iguatama - MG, proveniente de poços subterrâneos, em diversos pontos da rede de distribuição.

\section{MATERIAL E MÉTODOS}

As coletas de amostras de água foram realizadas no ano de 2017 no município de Iguatama-MG, totalizando em 120 amostras coletadas entre janeiro e julho, onde foram definidos previamente, 5 pontos para a realização das amostragens. Já a localização dos pontos de amostragem pode ser vista no quadro 1. A água utilizada no abastecimento do município é proveniente de poços subterrâneos, passando apenas pela etapa de cloração para tratamento, antes do recalque para reservatórios elevados.

QUADRO 1 - Identificação, localização e coordenadas dos pontos de amostragem de água.

\begin{tabular}{|c|c|c|c|}
\hline Pontos & Descrição & Latitude & Longitude \\
\hline P1 & $\begin{array}{c}\text { Reservatório - localizado na rua 11, no } \\
\text { centro do município }\end{array}$ & $20^{\circ} 10^{\prime} 49.31$ " S & $45^{\circ} 42^{\prime} 24.65^{\prime \prime} \mathrm{O}$ \\
\hline P2 & $\begin{array}{c}\text { Reservatório - localizado na rua 18, no } \\
\text { centro do município }\end{array}$ & $20^{\circ} 10^{\prime} 37.64 " \mathrm{~S}$ & $45^{\circ} 42^{\prime} 25.03^{\prime \prime} \mathrm{O}$ \\
\hline P3 & $\begin{array}{c}\text { Torneira - localizado na sede do SAAE, } \\
\text { na rua 18, no centro do município }\end{array}$ & $20^{\circ} 10^{\prime} 37,16^{\prime \prime} \mathrm{S}$ & $45^{\circ} 42^{\prime} 24.30^{\prime \prime} \mathrm{O}$ \\
\hline P4 & $\begin{array}{c}\text { Reservatório - localizado na rua 74, no } \\
\text { bairro Alto São Francisco }\end{array}$ & $20^{\circ} 10^{\prime} 58.30^{\prime \prime} \mathrm{S}$ & $45^{\circ} 43^{\prime} 08.13^{\prime \prime} \mathrm{O}$ \\
\hline P5 & $\begin{array}{c}\text { Torneira - localizada em uma rua, no } \\
\text { bairro de Garças de Minas }\end{array}$ & $20^{\circ} 11^{\prime} 11.23^{\prime \prime} \mathrm{S}$ & $45^{\circ} 41^{\prime} 09.57^{\prime \prime} \mathrm{O}$ \\
\hline
\end{tabular}


Para a realização das análises dos parâmetros físico-químicos, as amostras foram coletadas em frascos PET, previamente lavados com água do ponto de amostragem, com a capacidade de aproximadamente 0,5 litros. Já as coletas destinadas às análises microbiológicas foram realizadas em frascos de vidro roscáveis autoclavados, capazes de suportar temperaturas de até $300{ }^{\circ} \mathrm{C}$.

Após as coletas, as amostras eram devidamente identificadas com endereço do ponto de coleta, hora, nome do coletor e o número correspondente da amostra. Logo depois armazenadas em caixa térmica com gelo e enviadas ao laboratório do Serviço Autônomo de Água e Esgoto (SAAE) do município de Pains - MG para a realização das análises de qualidade de água. $\mathrm{O}$ ponto de coleta $\mathrm{P} 1$ é um reservatório que possui aproximadamente capacidade de 50 mil litros de água, abastecendo em torno de $20 \%$ da população localizada na área urbana do município. Este é caracterizado como reservatório elevado e localiza-se no ponto mais alto da cidade

O ponto de coleta P2 é um reservatório que possui aproximadamente capacidade de 600 mil litros de água, abastecendo a maioria da população da área urbana do município, cerca de $40 \%$. Ele é caracterizado como reservatório semienterrado e localiza-se no terreno da sede do SAAE.

O ponto de coleta P3 é uma torneira que se localiza no prédio da sede do SAAE, e serve para obter a qualidade da água proveniente do reservatório localizado na rua 18, no centro do município. Já o ponto de coleta P4 é um reservatório que possui aproximadamente capacidade de 50 mil litros de água, responsável por abastecer cerca de $10 \%$ da população urbana do município. Ele é caracterizado como reservatório apoiado e localiza-se no bairro Alto São Francisco

O ponto de coleta P5 é uma torneira que se localiza em uma residência do bairro de Garças de Minas, também perímetro urbano do município. A análise da água proveniente desta torneira é responsável por fornecer os dados de qualidade tanto da água proveniente do poço localizado no bairro, quanto das residências da região.

\section{Parâmetros analisados}

Os parâmetros analisados foram: coliformes totais, Escherichia coli, bactérias heterotróficas, cloro residual livre, cor aparente, $\mathrm{pH}$ e turbidez. As análises de Coliformes totais e Echerichia coli foram realizadas no mesmo dia das coletas, com uso de substrato definido enzimático para análise de coliformes totais e Escherichia coli, conhecido como sistema Colilert (sistema patenteado por IDEXX Laboratories), que utiliza nutrientes (açúcares ligados a radicais orgânicos cromogênicos) que fazem com que os microrganismos de interesse presentes na amostra produzam uma mudança de cor. Após o período de incubação se a cor amarela é observada, coliformes totais estão presentes, enquanto que, se a fluorescência azul é observada na presença de luz ultravioleta a $365 \mathrm{~nm}$, Escherichia coli está presente no sistema. Além de maior precisão, esse método tem como vantagem o tempo de resposta, já que a determinação simultânea de coliformes totais e Escherichia coli é efetuada após incubação a $35^{\circ} \mathrm{C}$ por 24 horas.

Já as análises de bactérias heterotróficas foram feitas pela técnica "Pour Plate", é conhecida também como técnica em profundidade. A execução do ensaio consiste inicialmente em colocar as placas de Petri Film sobre uma superfície plana, levantar o filme superior e com o auxílio de uma pipeta estéril colocar 1 (um) $\mathrm{ml}$ de amostra no centro do filme inferior. Depois deixar o filme superior cair sobre a amostra inoculada. Quando todas as placas estavam prontas, elas foram encubadas numa 
estufa bacteriológica por um período de 24 horas a uma temperatura de $35{ }^{\circ} \mathrm{C}$ a 38 ${ }^{\circ} \mathrm{C}$. Por fim quando a encubação estava pronta foi necessário fazer a contagem das colônias com um auxílio de um contador de colônias.

Para se obter o teor de cloro presente no sistema foi utilizado um procedimento que consistiu em adicionar $10 \mathrm{ml}$ de água do sistema analisado no clorímetro digital portátil. Depois se adicionou dois reagentes químicos, primeiramente o tampão e logo depois o indicador. Após esse procedimento, observou-se se a coloração da água modificou. Caso ela fique com uma coloração rosada, significa que há presença de cloro na amostra. A Portaria n 2914/2011 do Ministério da Saúde (BRASIL, 2011) determina a obrigatoriedade de se manter, no mínimo, 0,2 mg/l de cloro residual livre ou $2 \mathrm{mg} / \mathrm{l}$ de cloro residual combinado em toda a extensão do sistema de distribuição (reservatório e rede). Também recomenda que o teor máximo de cloro residual livre em qualquer ponto do sistema de abastecimento seja de $2 \mathrm{mg} / \mathrm{l}$.

As análises de cor aparente foram feitas no aparelho denominado colorímetro, modelo AquaColor DQO, com faixa de medição de 0 a 500 PtCo. Para determinação, a amostra é transferida até a linha de marcação de $10 \mathrm{~mL}$. Segura-se então a cubeta pela tampa, procedendo-se a limpeza de seu exterior com um papel absorvente, certificando-se de que não haver nenhuma mancha ou poeira. Feito este procedimento, a cubeta era introduzida no aparelho para realização da leitura.

Para a obtenção de $\mathrm{pH}$ das amostras, foi utilizado o pHmetro microprocessado de bancada. Este equipamento depois de calibrado corretamente, mede $\mathrm{o} p \mathrm{pH}$ mergulhando-se o eletrodo e o sensor de temperatura dentro da amostra por cerca de 2 minutos.

Para turbidez, as análises foram feitas com um turbidímetro de bancada digital e um kit padrão de turbidez, contendo 1 cubeta de $25 \mathrm{ml}, 5$ padrões prontos com os valores 0,1 NTU, 0,8 NTU, 0,8 NTU, 0,8 NTU e 1000 NTU. Depois da calibração com cada um dos padrões, a amostra é adicionada a uma cubeta vazia de $25 \mathrm{ml}$ para leitura.

\section{RESULTADOS E DISCUSSÃO}

Os gráficos box-plots relativos ao parâmetro cloro residual livre são apresentados na Figura 1.

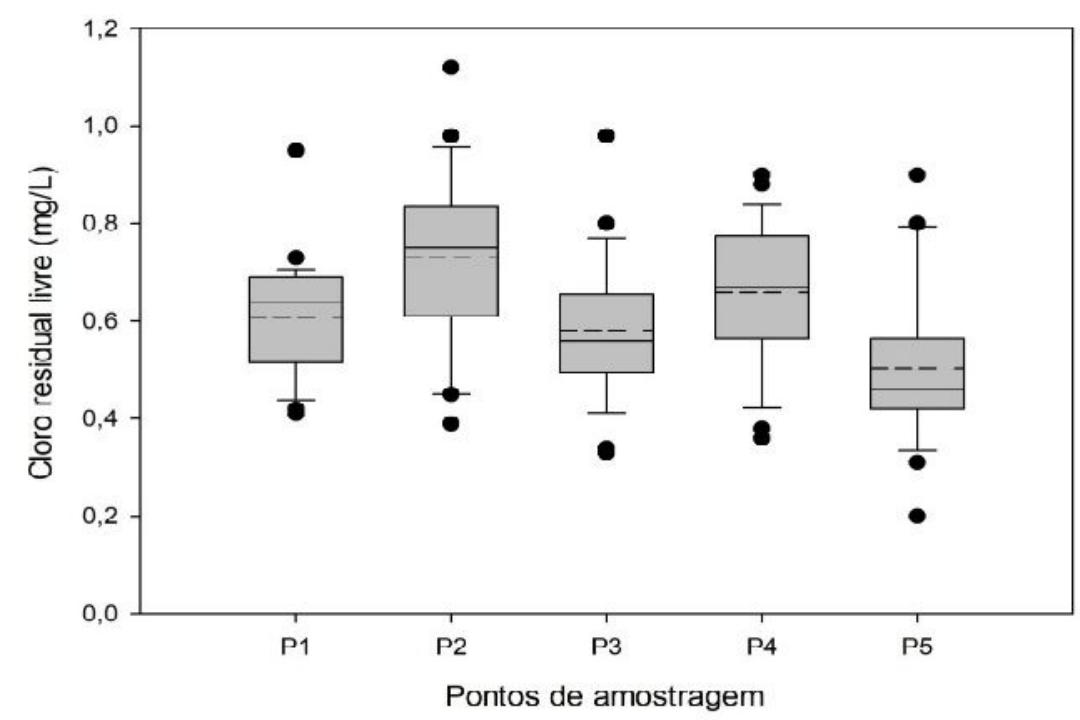

FIGURA 1 - Box-plots dos valores de cloro residual obtido para os pontos avaliados 
Brasil (2011) apresenta claramente a necessidade de cloração da água, sendo importante observar os limites, tanto máximo, pois pode ocasionar rejeição dos consumidores, quanto o mínimo, para que ocorra a desinfecção adequada. As amostras coletadas apresentaram uma alta variabilidade dos valores obtidos de cloro residual livre, porém, os valores definidos como outliers superiores não superaram o limite máximo estabelecido por Brasil (2011), que recomenda a manutenção de cloro residual livre de no mínimo entre $0,2 \mathrm{mg} / \mathrm{l}$ e máximo $2 \mathrm{mg} / \mathrm{l}$ - de acordo com o apresentado, todas as avaliações realizadas se mantiveram entre 0,2 $\mathrm{mg} / \mathrm{l} \mathrm{e} 1,2 \mathrm{mg} / \mathrm{l}$. Segundo Silva et al. (2016) após adição de cloro ocorre a eliminação das bactérias comprovando assim a eficiência do tratamento utilizado para remoção de microrganismos indicadores. Os box-plots relativos ao parâmetro de cor aparente são apresentados na Figura 2.

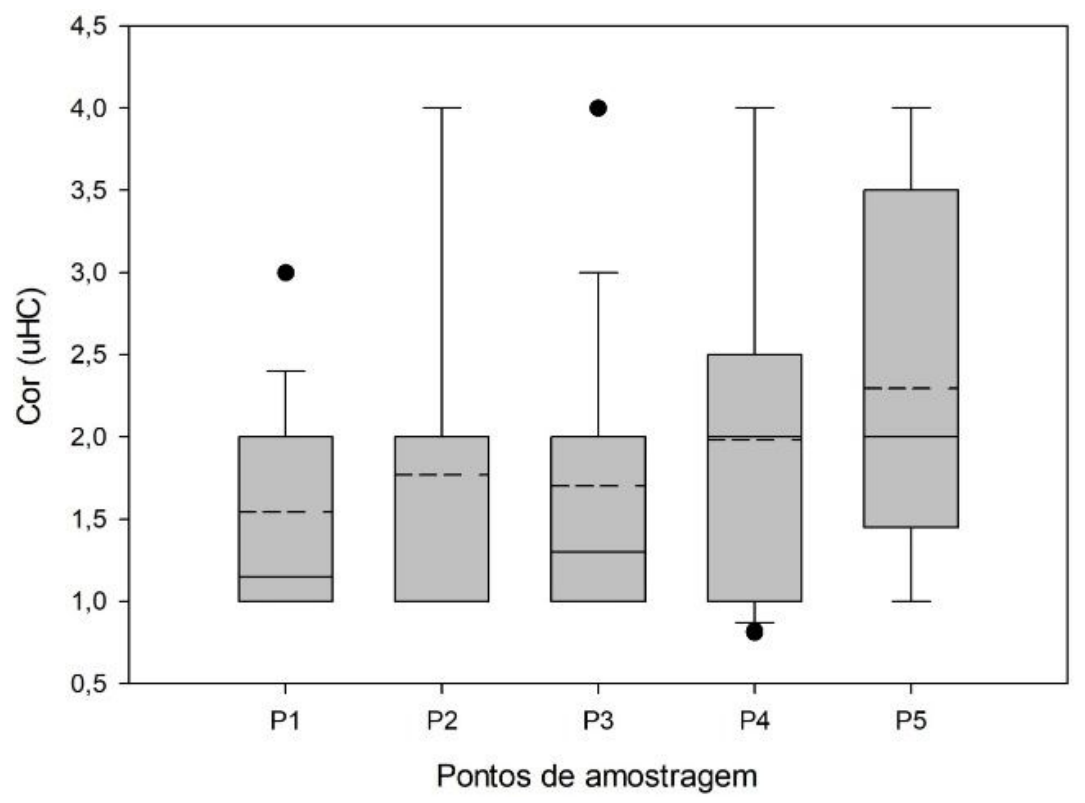

FIGURA 2 - Box-plots dos valores de cor aparente obtidos para os pontos avaliados

A cor aparente é um parâmetro físico de controle exigido pela Portaria $\mathrm{n}^{0}$ 2914/2011 do Ministério da Saúde (BRASIL, 2011) para águas destinadas ao consumo humano, devido à aparência estética adequada que esta deve apresentar. O valor máximo permissível é de $15 \mathrm{uHC}$, o que foi obtido neste estudo.

Pela a análise da Figura 2, tem-se que P1 apresenta menor variabilidade de dados se comparado com os demais pontos analisados, a linha da mediana próxima ao primeiro quartil, demonstra que os dados são positivamente assimétricos, enquanto P2, P4 e P5 apresentaram uma ampla variação de dados.

Em diferentes estações e também de acordo com a etapa do tratamento de água a diferença no valor de cor obtido é simbólica, como por exemplo no período chuvoso, o valor obtido de cor geralmente é maior do que o valor obtido no período de seca e na água in natura o valor também é maior do que o valor obtido na água após decantação (SILVA et al. 2016). Já os box-plots relativos ao parâmetro de pH são apresentados no Figura 3. 


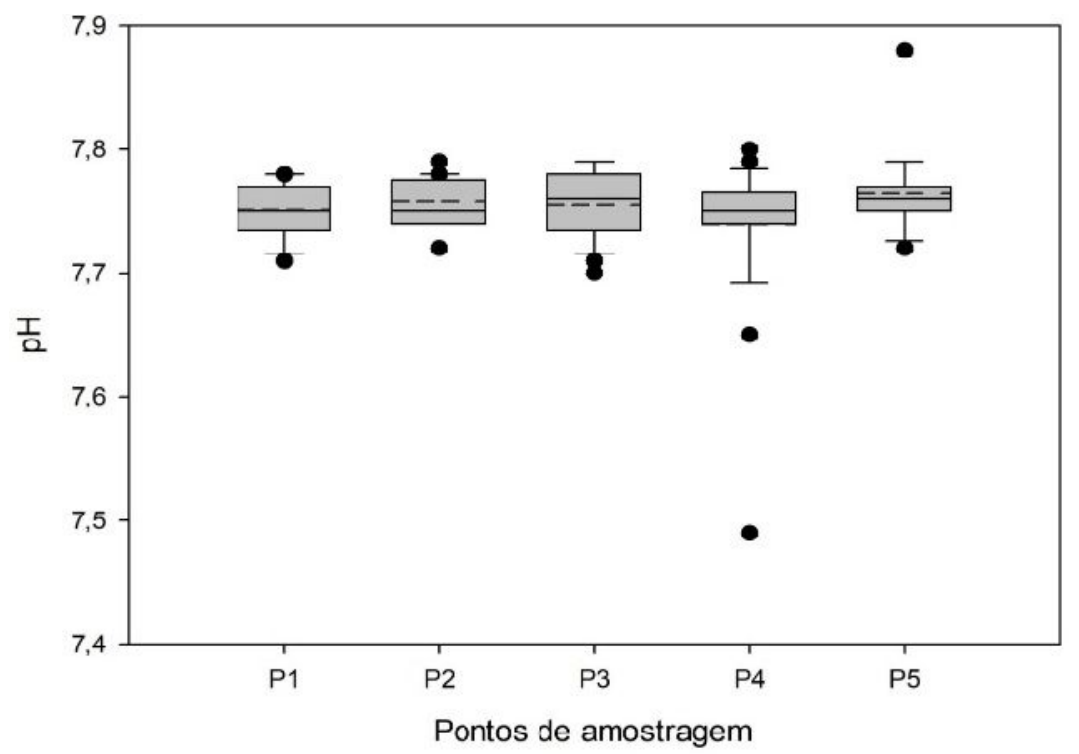

FIGURA 3 - Box-plots dos valores de pH obtidos para os pontos avaliados

De acordo com os resultados, todas as amostras se enquadraram aos valores de referência apresentados em Brasil (2011) para pH (entre 6 e 9,5), sendo os obtidos neste estudo variando entre 7,49 e 7,88. Em águas com pH baixo há o comprometimento de seu sabor e há aumento de seu potencial corrosivo, enquanto que águas com pH elevado, além de também terem seu sabor comprometido, aumentam a formação de incrustações nas redes ou aparelhos sanitários (BIRKHEUER et al., 2017), o que não foi observado neste estudo, já que os valores de $\mathrm{pH}$ observados podem serem considerados neutros.

Segundo pesquisa de Fernandes (2011), que determinou a qualidade da água subterrânea em propriedades rurais do município de Planalto - $\mathrm{RS}$, o pH de todas as amostras estavam dentro do padrão da legislação, resultados semelhantes aos determinados no presente estudo para água utilizada no sistema de abastecimento. Os box-plots relativos ao parâmetro de teor de turbidez são apresentados no Figura 4.

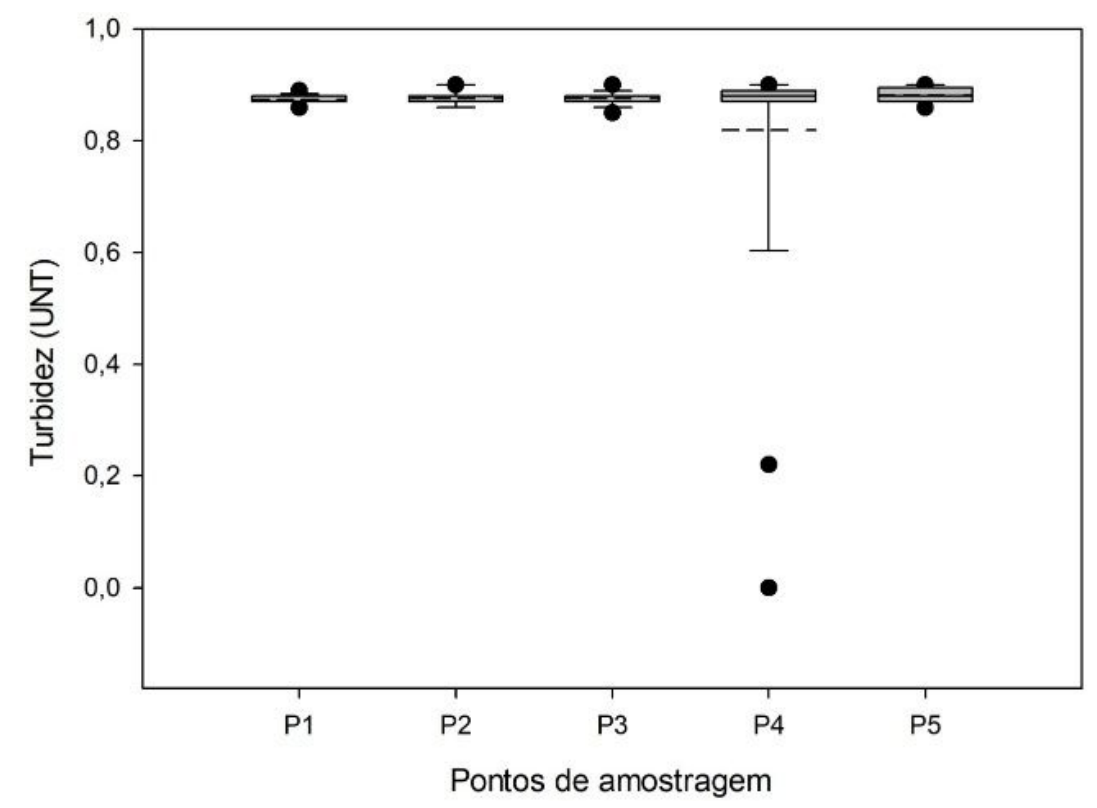

FIGURA 4 - Box-plots dos valores de turbidez obtidos para os pontos avaliados 
Na Portaria no 2914/2011 do Ministério da Saúde (BRASIL, 2011) é estipulado o valor máximo de 5,0 UNT (unidades nefolométricas de turbidez) para a água de abastecimento. Os resultados apresentados no Figura 4 mostram que todas as amostras de água se encontram abaixo do valor máximo permitido, sendo os outliers, encontrados em P4 inferiores ao valor mínimo definido para o box-plot, fato este interessante em termos de qualidade da água para abastecimento.

De acordo com Oliveira et al. (2018), a turbidez é causada por qualquer material em suspensão, como por exemplo, plânctons, bactérias, argila, areia e poluição de forma geral. Esta, além de causar uma má aparência visual, pode acarretar em um elevado índice de componentes dissolvidos, desde matéria orgânica, até microrganismos patogênicos, podendo causar a contaminação de produtos.

A temperatura da água não é parâmetro de classificação para águas naturais, segundo a resolução 357 do CONAMA (BRASIL, 2011), porém a faixa mais desejável de temperatura para o abastecimento de público de água está entre 4,4 a $10{ }^{\circ} \mathrm{C}$, para agradar o paladar dos consumidores (BRANCO, 1991). Assim, são apresentados no Figura 5, os box-plots relativos ao parâmetro de temperatura.

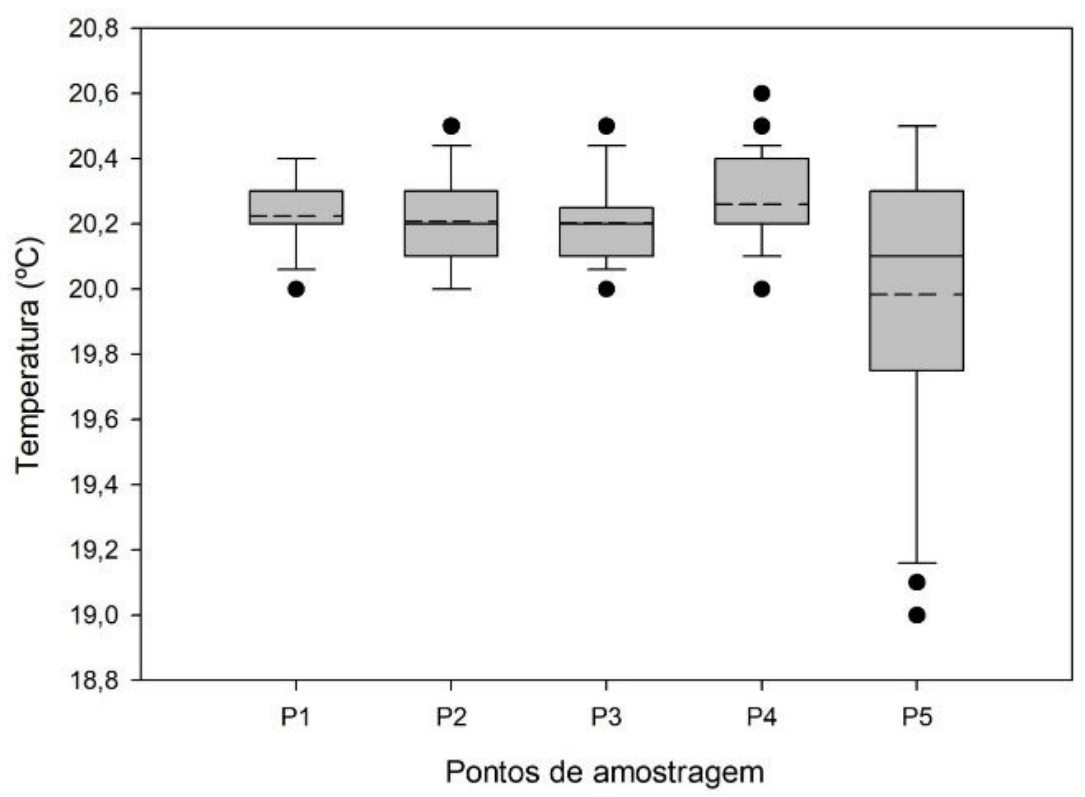

FIGURA 5 - Box-plots dos valores de temperatura obtidos para os pontos avaliados

Para a temperatura, em todo o período de coleta, foi registrada uma variação de temperatura entre $19^{\circ} \mathrm{C}$ e $20,6{ }^{\circ} \mathrm{C}$. A elevada temperatura observada nas amostras é resultado da influência da exposição dos tubos de PVC responsáveis pela condução da água à radiação solar.

É possível observar que todos os valores obtidos ficaram acima do recomendável para promover sensação agradável aos consumidores ao utilizarem a água para dessedentação, sendo obtida maior variabilidade dos valores medidos de temperatura para o ponto P5. Quanto a coliformes totais, Escherichia coli e bactérias heterotróficas, em todas as análises obteve-se ausência dos três parâmetros, logo, obedecendo às normas impostas pela Portaria no 2914/2011 do Ministério da Saúde (BRASIL, 2011) para águas destinadas ao consumo humano. A presença de E. coli traz indícios sobre contaminação fecal e, consequentemente, a possibilidade de haver presença de microrganismos patogênicos na água. 
Scalize et al. (2014) observaram que a água para abastecimento em um assentamento de reforma agrária em Canudos, no estado de Goiás, proveniente também de poços, porém rasos e/ou pouco profundos, apresentou em $100 \%$ das amostras coletadas em seu estudo, presença de E. Coli, diferentemente do obtido neste estudo. Salienta-se então a importância da forma de execuação e manutenção de poços subterrâneos utilizados para abastecimento urbano, de forma a se manter a integridade do poço e principalmente da água ofertada.

Além disso, salienta-se a possível necessidade de tratamento do recurso hídrico, mesmo que simplificado, como é realizado no município de Iguatama. No mesmo estudo supracitado, foram encontrados valores de turbidez média entre 1,1 e 3,6 UNT, o que também indica qualidade inferior da água em comparação ao obtido neste estudo.

Em estudo realizado por Scuracchio e Farache Filho (2011), no qual o objetivo era avaliar a qualidade da água consumida em escolas e creches municipais da cidade de São Carlos - SP, foram realizadas amostragem na entrada da rede, nos reservatórios e nos filtros domésticos, sendo que, os autores observaram que os filtros foram os maiores responsáveis pela depreciação da qualidade da água, em relação ao aumento de bactérias heterotróficas e redução do teor de cloro, aumentando, portanto, o risco de doenças, então, tem-se que mesmo que a concentração de cloro residual livre se mantenha em valores definidos como ótimos na rede de abastecimento, estes valores podem alterar-se na rede da instalação predial de água das edificações, o que não foi observado evidentemente neste estudo, estando as concentrações avaliadas para este parâmetro em P5, 'definido em uma torneira de uma instalação hidráulica predial de água fria no perímetro urbano do município de Iguatama, similares às obtidas nos pontos de coleta localizados nos reservatórios da concessionária.

Em comparação à qualidade microbiológica das águas avaliadas neste trabalho, em estudo realizado por Guerra et al. (2006), foi verificado que 0,3\% das amostras de água utilizadas para consumo humano, apresentaram concentração de bactérias heterotróficas acima de $500 \mathrm{UFC} / \mathrm{mL}$. Já no estudo realizado por Domingues et al. (2007), das 22 amostras provenientes de reservatório, 10 (43,5\%) não atenderam ao padrão estabelecido pela legislação vigente para este parâmetro de qualidade, o que não foi observado para o município de Iguatama.

\section{CONCLUSÃO}

Foi possível determinar a conformidade da qualidade da água utilizada para abastecer a população da cidade de Iguatama - MG com a Portaria no 2914/2011 do Ministério da Saúde. Ainda é relevante mencionar que a dita qualidade foi constatada como satisfatória em todos os aspectos analisados.

Pôde-se avaliar que os resultados obtidos nas análises da água estudada estão de acordo com parâmetros impostos pela legislação vigente. Assim, têm-se que o uso de água explorada de mananciais subterrâneos é vantajoso, pois apresenta uma elevada qualidade biológica e físico-química, restando ao tratamento de água de Iguatama - MG, apenas a etapa cloração, mas não descartando outras fases, se necessário.

\section{Declaração de conflitos de interesses}

Os autores do artigo afirmam que não houve nenhuma situação de conflito de interesse, tais como propostas de financiamento, emissão de pareceres, promoções 
ou participação em comitês consultivos ou diretivos, entre outras, que pudessem influenciar no desenvolvimento do trabalho.

\section{REFERÊNCIAS}

ARAÚJO, D. R.; MENDONÇA, A. S. F.; REIS, J. A. T. dos. Análise de variação e comparação de índices de estado trófico: reservatórios dos aproveitamentos hidrelétricos de Rio Bonito e Suíça. Engenharia Sanitária e Ambiental. v. 23, n. 1, p. 55-62, 2018. Disponível em: < http://www.scielo.br/scielo.php?script=sci_abstract\&pid=S1413$41522018000100055 \&$ Ing=pt\&nrm=iso $>$. doi: $10.1590 /$ s1413-41522018162462.

BIRKHEUER, C. de. F.; ARAÚJO, J. de.; REMPEL, C.; MACIEL, M. J. Qualidade físico-química e microbiológica da água de consumo humano e animal do brasil: análise sistemática. Revista Caderno Pedagógico, v. 14, n. 1, p. 134-145, 2017. Disponível em: <http://www.univates.br/revistas/index.php/cadped/article/view/1423 >. doi: 10.22410/issn.1983-0882.v14i1a2017.1423.

BORGES, P. P.; MACHADO, K. B.; CUNHA, H. F. da.; NABOUT, J. C. Exploração de águas subterrâneas por meio de poços tubulares no estado de Goiás: relações demográficas, socioeconômicas e tendências de uso. Revista de Biotecnologia \& Ciência, v. 3, n. 1, 2014. Disponível em: < http://www.revista.ueg.br/index.php/biociencia/article/view/2492 >.

BRANCO, S. M. Água e o homem. Hidrologia Ambiental. EDUSP (Editora da Universidade de São Paulo). São Paulo, 1991. 35 p.

CAMARGO-CRUZ, P. E. A. Distribuição espacial-temporal das internações por doenças infecciosas intestinais no estado de São Paulo, para a faixa etária de 5 a 14 anos, entre 2001 e 2010. Atas de Saúde Ambiental, v. 5, p. 85-104, 2017. Disponível em: < http://www.revistaseletronicas.fmu.br/index.php/ASA/article/download/1388/1239>.

BRASIL. Ministério da Saúde. Portaria n 2.914 de 12 de dezembro de 2011. Diário Oficial da República Federativa do Brasil, Brasília, 2011. 21 p. Disponível em: < http://bvsms.saude.gov.br/bvs/saudelegis/gm/2011/prt2914_12_12_2011.html>

DOMINGUES, V. O; TAVARES, G. D.; STUKER, F.; MICHELOT, T. M.; REETZ, L. G. B.; BERTONCHELI, C. M.; HORNER, R. Contagem de bactérias heterotróficas na água para consumo humano. Revista Saúde, v.33, n.1, p.15-19, 2007. Disponível em: < https://periodicos.ufsm.br/revistasaude/article/viewFile/6458/3926>.

FUNASA, Fundação Nacional de Saúde. Manual de saneamento. 4 ed. Brasília: Assessoria de Comunicação e Saúde, Brasília, 2015. 642 p.

GOMES, H.; JESUS, A. G. de.; OlIVEIRA, A. P. R.; CORREAA, G. M.; CUNHA, T. C. Perfil epidemiológico das doenças relacionadas com a água no município de Conceição do Araguaia, Pará. Revista Movimenta, v. 9, n.1, p. 48-61, 2016. Disponível em: http://www.revista.ueg.br/index.php/movimenta/article/view/3574/3150>. 
GUERRA, N. M. M.; OTENIO, M. H.; SILVA, M. E. Z.; GUILHERMETTI, M.; NAKAMURA, C. V.; NAKAMURA, T. U.; DIAS FILHO, B. P. Ocorrência de Pseudomonas aeruginosa em água potável. Acta Scientiarum Biological Sciences, v.28, n.1, p.13-18, 2006. Disponível em: < http://periodicos.uem.br/ojs/index.php/ActaSciBiolSci/article/view/1053>. . doi: 10.4025/actascibiolsci.v28i1.1053.

LIBÂNIO, M. Fundamentos de qualidade e tratamento de água. 3 ed. Editora Átomo, 2010. 496 p.

OLIVEIRA, N. T.; NASCIMENTO, K. P.; GONÇALVES, B. de. O.; LIMA, F. C. de.; COSTA, A. L. N. da. Tratamento de água com moringa oleífera como Coagulante/floculante natural. Revista Científica da Faculdade de Educação e Meio Ambiente Ariquemes: FAEMA, v. 9, n. 1, p. 373-382, 2018. Disponível em: < http://www.faema.edu.br/revistas/index.php/Revista-FAEMA/article/view/539>. doi: 10.31072/rcf.v9i1.539.

RIBEIRO, M. C. M. Nova portaria de potabilidade da água: Busca de consenso para viabilizar a melhoria da qualidade da água potável distribuída no Brasil. Revista DAE, $\quad$ n. 189, $2012 . \quad$ Disponível em <http://revistadae.com.br/downloads/Revista_DAE_Edicao_189.pdf>.

SCURACCHIO P. A.; FARACHE FILHO A. Qualidade da água utilizada para consumo em escolas e creches no município de São Carlos - SP. Revista Alimentos e Nutrição, v. 22, n. 4, p. 641-647, 2011. Disponível em: < http://servbib.fcfar.unesp.br/seer/index.php/alimentos/article/viewFile/1495/1165>.

SILVA, L. J.; LOPES, L. G.; AMARAL, L. A. Qualidade da água de abastecimento público do município de Jaboticabal, SP. Engenharia Ambiental e Sanitária, v. 21, n. 3, p. 615-622, 2016. Disponível em: < http://www.scielo.br/pdf/esa/v21n3/18094457-esa-21-03-00615.pdf>. doi: 10.1590/S1413-41522016121151.

SCALIZE, P. S.; BARROS, E. F.; SOARES, L. A.; HORA, K. E. R.; FERREIRA, N. C.; BAUMANN, L. R. F. Avaliação da qualidade da água para abastecimento no assentamento de reforma agrária Canudos, Estado de Goiás. Revista Ambiente e Água, v. 9, n. 4, p. 696-707, 2014 . Disponível em: < http://www.scielo.br/scielo.php?pid=S1980993X2014000400012\&script=sci_abstract \&tlng=pt>. doi: 10.4136/ambi-agua. 1386 .

VILLAR, P. C. Groundwater and the right to water in a context of crisis. Ambiente \& Sociedade, v. 19, n. 1, p. 85-102, 2016. Disponível em: < http://www.scielo.br/scielo.php?script=sci_arttext\&pid=S1414-753X2016000100006>. doi: 10.1590/1809-4422asoc150126r1v1912016.

XAVIER, F.; SILVA, R. W. da. C.; FILHO, W. M.; MOREIRA, C. A. Emprego da sondagem elétrica vertical integrada às análises químicas e microbiológicas no diagnóstico preliminar da contaminação do solo e da água subterrânea no cemitério municipal da cidade de Rio Claro (SP). Engenharia Sanitária e Ambiental., v. 23, n. 2, p. 333-344, 2018. Disponível em: <http://www.scielo.br/scielo.php?pid=S141341522018000200333\&script=sci_abstract\&tlng=pt>. doi: 10.1590/s141341522018152375. 